\title{
VOCABULARY AND LANGUAGE TEACHING
}

\section{Abrudan Cristina \\ Universitatea din Oradea Facultatea de Stiinte Economice}

In this paper we have looked at the difference between teaching language structure and teaching vocabulary. We have discussed how counts of frequency alone are not enough to determine what words should be taught. We have seen that knowing a word means more than just knowing its meaning. Even that is problematical since meaning includes sense relations and context, for example. To know a word we also need to know about its use, how it is formed and what grammatical behavior it provokes. Above all, in this paper, we have approached the idea of how vocabulary teaching and learning need to be emphasized in order for students to be competent language users.

Keywords: vocabulary, teaching vocabulary, learning vocabulary, word selection. Jel Code: Y8

To the non-language specialist, the common sense view of how languages are learned is that you substitute the words in your first language for the corresponding words in the second language. Words represent the building block upon which knowledge of the second language can be built. Armed with this common sense but naïve view, non-specialists would therefore be surprised if they were to survey the history of language teaching. Far from being regarded of pivotal importance in language learning, the status of vocabulary in the last 50 years has, on the whole, been relatively low. For many years, vocabulary was seen as incidental to the main purpose of language teaching - more exactly the acquisition of grammatical knowledge about the language. Vocabulary was absolutely necessary to give students something to hang on when learning structures, but was frequently not a main focus for learning itself. Recently, however, linguists have increasingly been turning their attention to vocabulary, stressing its importance in language teaching and reassessing some of the ways in which it is taught and learnt.

Nowadays, people are more and more aware of the fact that the acquisition of vocabulary is just as important as the acquisition of grammar, although the two are obviously interdependent. If language structures make up the skeleton of a language, the vocabulary provides the flesh and the vital organs. Vocabulary is the knowledge of words and word meanings. As Steven Stahl (2005) puts it, "Vocabulary knowledge is knowledge; the knowledge of a word not only implies a definition, but also implies how that word fits into the world." Vocabulary knowledge is not something that can ever be fully mastered; it is something that expands and deepens over the course of a lifetime. Instruction in vocabulary involves far more than looking up words in a dictionary and using the words in a sentence. Vocabulary is acquired incidentally through indirect exposure to words and intentionally through explicit instruction in specific words and wordlearning strategies.

Unless words are used, an ability to manipulate language structures does not have any potential for expressing meaning. Here we talk about the importance of choosing one's words carefully. In the real life it is possible that where vocabulary is used correctly, it can cancel out grammatical inaccuracy. The need to study language structures is obvious, as grammatical knowledge allows us to generate correct sentences. However, at the same time, we must have meanings that we wish to express, and we need to have a store of words that we can select from when we wish to express these meanings.

A common problem in teaching vocabulary lies in the fact that whilst there is a consensus about at what levels grammatical structures should be taught, we can hardly say about teaching vocabulary. Of course, there are syllabuses that include word lists, but there is no guarantee that 
the list for a set of students is the same with the list for another set of students at the same level. But, in the same time we can say students have to learn the use of the verb 'to be' before they learn its use as an auxiliary in the Present Continuous Tense.

One of the problems of vocabulary teaching is how to select what words to teach. Dictionaries for upper intermediate students frequently contain up to 55,000 words or even more, and a word may have many meanings. They represent just a small fraction of all the possible words in a language. For a second-language speaker to get to native-speaker level takes many years of hard work. One would have to double the size of the active vocabulary at least. Some linguists estimate that educated native speakers could have an active vocabulary of between 8,000 and 10,000 words. Good second-language speakers might have an active vocabulary of 3,500 words. That is quite a difference.

Frequency has been a general principle of vocabulary selection. The criteria of how frequently some certain words are used can help us decide which words we should teach. The words which are most commonly used are the ones we should teach first. Another principle that has been used in selecting the vocabulary is that of coverage. A word is more used if it covers more things than if it only has a specific meaning. In order to know which words are the most frequently used, we can read lists containing the most often used words in a certain language. This was done by Michael West who scanned newspapers and books in order to list his frequency tables.

Perhaps the greatest revolution in vocabulary investigation and design, however, has been the harnessing of the computer to the task of finding out which words are used and how they are used. The massive Cobuild computer-based corpus at Birmingham University has been used not only for the design of a learner's dictionary but also as a resource for a vocabulary driven course book. That is the usefulness of the computer, of course: you can key in a word and it will immediately give you examples showing you the sentence s and phrases the word occurs in and how often it is used. The Internet itself is an almost perfect learning space. It should be possible, then, to design vocabulary syllabuses on the basis of computerized information. If we feed in enough text, from newspapers, magazines, books, letters, conversations, and so on, we will be able to make accurate statements about what words to teach. There is no doubt at all that the use of the computers has gained enormously from the information they have been able to access. But even with such scientific power at our fingertips, the problem of selection has not been completely solved.

The first thing to realize about vocabulary items is that they frequently have more than one meaning. The word "book" for example, obviously refers to something you use to read from, "a set of printed papers fastened together inside a cover, as a thing to be read." according to the Concise Oxford Dictionary. But the same dictionary continues in giving eight more meanings of the word as a noun, two more meanings of "book" as a verb and three meanings where "book" + preposition makes phrasal verbs. So, we will have to say that the word "book" means the kind of thing you read from but it can also mean a number of other things, too. What a word means can be changed, stretched or limited by how it is used and this is something students need to know about. Word meaning is frequently stretched through the use of metaphor and idiom. Word meaning is also governed by collocation - that is which words go with each other. But words can change their shape and their grammatical value, too. Students need to know facts about word formation and how to twist words to fit different grammatical contexts. And they also need to know how suffixes and prefixes work. How can we make the words potent and expensive opposite in meaning? Why do we preface one with -im and the other with -in? Students need to know also how words and spelt and how they sound. Indeed the way words are stressed - and the way that stress can change when their grammatical function is different - as with nouns and verbs, for example, is vital if students are able to understand words and use words in speech. Part of learning a word is learning its written and spoken form. 
Thus, we come to the conclusion that teaching vocabulary is obviously more than just presenting new words. This may, of course, have its place, but there are some other things to be discussed, too. For example, students see a lot of words during one week, some of them are used straight away, others are not. The question is the following: Should we teach some words which we need for structure practice, for example, and not teach others which occur incidentally in reading texts, for example? Is there any way in which we can encourage students to really learn a word?

Experiments on vocabulary seem to suggest that students remember best when they have actually done something with the words they are learning. There is a definite advantage in getting students to do more than just repeat them. Tasks such as changing them to mean their opposites, making a noun an adjective, putting words together, etc, help to fix the words in the learners' minds. One way or another, we have to get students interact with words. We should get them to "adopt" words they like and that they want to use. We should get them to do things with words so that they become properly acquainted with them. Especially at intermediate levels and above, discovery techniques - where students have to work out rules and meanings for themselves, rather than being given everything by the teacher, represent an appropriate alternative to standard presentation techniques. This is certainly true of vocabulary learning where students will often be asked to discover for themselves what a word means and why and how it is being used.

At intermediate levels we can assume the students already have a considerable store of vocabulary. Rather than teach them new words we can show them examples of words in texts and ask them to use their previous knowledge to work out what words can go with others, when they should be used and what connotations they have. Discovery techniques used with vocabulary materials allow students to activate their previous knowledge and to share what they know (if they are working with others). The conclusion we can draw from this discussion about active and passive vocabulary and about interacting are best summed up by a quote from Adrian Underhill: "...engaging the learner... is essential to any activity that is to have a high learning yield." (Underhill 1985:107)

We have already said that selecting words for teaching purposes is avery difficult task to do. We based this on the enormous number of words that any language contains. For the same certainly students will want to enlarge their vocabulary with many more words than we, their teachers, can teach them. Where can they get this information? Certainly dictionaries provide one of the best resources for students who wish to increase the number of words they understand, or at least for students who wish to understand what a word means when they come across it in a text or a conversation. Most students will consult a bilingual dictionary to find the equivalent in their language. There is nothing wrong with such dictionaries except for the fact that they do not usually provide sufficient information for the students to be able to use. Perhaps the greatest resource we can give our students is a good monolingual dictionary. They provide information about pronunciation, spelling, word formation, metaphorical and idiomatic use - the entire profile of a particular word. The fact that students do not use monolingual dictionaries very much is not just because of language difficulty, however. Dictionaries are very daunting precisely because they contain so much technical information. Unless we train students in how to understand the information and use the dictionaries, the money they spend in buying them will be largely wasted since they never open them.

The scientific research on vocabulary instruction reveals that most vocabulary is acquired incidentally through indirect exposure to words. Students can acquire vocabulary incidentally by engaging in rich oral-language experiences at home and at school, listening to books read aloud to them, and reading widely on their own. Reading volume is very important in terms of longterm vocabulary development. Extensive reading gives students repeated or multiple exposures to words and is also one of the means by which students see vocabulary in rich contexts. Cunningham (2005) recommends providing structured read-aloud and discussion sessions and 
extending independent reading experiences outside school hours to encourage vocabulary growth in students.

It seems almost impossible to overstate the power of words; they literally have changed and will continue to change the course of world history. Perhaps the greatest tools we can give students for succeeding, not only in their education but more generally in life, is a large, rich vocabulary and the skills for using those words. Our ability to function in today's complex social and economic world is affected by our language skills and word knowledge. In addition to the vital importance of vocabulary for success in life, a large vocabulary is more specifically predictive and reflective of high levels of reading achievement.

\section{Bibliography:}

1. Dylan, Clarke, Guessing the Meaning of Words From Context: Strategies and Techniques, Cambridge, 1980

2. Jeremy, Harmer, The Practice of English Language Teaching, Longman, 1991

3. Robert, Carter, Vocabulary and Language Teaching, Longman, 1987

4. Robert, Carter, Vocabulary, Longman, 1990

5. Marianne, Celce-Murcia, Teaching English as a Second or Foreign Language, Newbury House, 1991 